\title{
Beyond the bench: A conversation with Mayada Elsabbagh
}

\section{BY PETER HESS}

13 OCTOBER 2021

A lab is a bit like a kitchen, with a multitude of "dishes" simmering at once, says Mayada Elsabbagh, associate professor of neurology and neurosurgery at McGill University in Montreal, Canada. New students can feel lost in the flurry of activity, but Elsabbagh encourages them to dive in and contribute - most importantly, with their own ideas.

Elsabbagh scoops up that collective wisdom to keep her lab cooking. A committee of lab members at all career stages, for example, reads every graduate school application before deciding who gets the nod.

During the pandemic, her lab members have come together in other ways, too, leading one another in yoga and meditation workshops, quiz nights and a virtual drop-in gathering called 'cookie time.' The team-building helps with their mission: to discover how early social experiences and other environmental factors might protect against autism and related conditions.

Elsabbagh told Spectrum about her "neurotic scheduling" (and its limits), why she is not active on social media, and the secret to inbox zero.

\section{Spectrum: What big question drives your research?}

Mayada Elsabbagh: My research centers around understanding factors that influence early brain development, such as genetic factors that are rare in the general population. I'm particularly intrigued by the idea of resilience, and the possibility that the brain essentially adapts its own development to respond to situations of adversity.

On my sabbatical next year, we're planning to explore the intersection of disability and refugee status. This involves people who have experienced trauma and may show signs of disability. We plan to track the extent to which biological factors contributed to their trajectories, versus some of 


\section{Spectrum | Autism Research News}

https://www.spectrumnews.org

those traumatic experiences.

\section{S: Whose work do you admire?}

ME: The person who got me interested in the field to begin with was my late supervisor, Annette Karmiloff-Smith. She's very well known for her work on developmental trajectories, and she actually was the person who shifted my career trajectory toward an appreciation of issues around development. That's led to where I took my research today.

\section{S: What does a typical day look like for you?}

ME: Predictability is the only thing that I don't have in my schedule. I experience a perpetual sense of chaos. It's like cooking: There's many dishes going at the same time, and you're trying to shift gears between different modes of working, whether that's the deep thinking involved in writing and reviewing papers or the collaborative process of developing trial protocols. And from that chaos, I try to impose strategies to create order and get a few meaningful things done every day.

\section{S: What are those strategies?}

ME: Neurotic scheduling that I modify at the last minute anyway. Over the pandemic, I have gone from maintaining many to-do lists to fitting one list on a single page. So in a single glance, I can manage issues related to my work, my family and my health.

I also surround myself with extremely organized, talented, reliable people, knowing that I can trust my team to do the things that I miss and the things they're much better at doing, whether administrative, scientific or related to our interactions with families.

Another strategy that has worked extremely well for me is letting go of things that realistically won't happen and managing my guilt about not getting something done. And really trying to end each day with the feeling that at least one thing I did was meaningful and that this is what I wanted to be when I grew up.

\section{S: How much sleep do you get?}

ME: I absolutely cherish my eight hours of sleep, without which I will not have a productive day. There's also a coffee ritual in the morning, without which the day does not look very promising.

\section{S: When and where are you most productive?}

ME: I love working in cafes. In Montreal, that's not unusual. My house is in an area full of nature. 
That's my second-favorite spot, except that house fills up with people in the summer — family members come and stay with me - so no work gets done. Instead, a lot of cooking happens in the summer, and a lot of just hanging out. A lot of doing nothing happens in that house as well.

\section{S: Do you listen to anything while you work?}

ME: I like white noise, like what you get in a cafe.

\section{S: What is your favorite scientific conference?}

ME: Is it too controversial to say I don't love conferences? I increasingly find conferences, especially the big ones, overwhelming and kind of disappointing. When I go to a conference, my wish is to learn something new, meet somebody new and interesting, think differently about an issue or be inspired. And I find that larger conferences tend not to deliver those things. So recently, I started thinking about conferences as places where I catch up with people I don't see very often, making sure that I have fun scheduled alongside a minimalist list of the kind of science that I want to stay up to date with - usually the type that I don't do myself.

\section{S: Do you have any good conference memories?}

ME: At a workshop in Italy, we got served espressos in the morning and freshly cooked risotto for lunch. I kept thinking, "Why can't we just do this all the time?"

\section{S: What are you reading right now?}

ME: That's kind of a hard one on the heart, because I am not reading for leisure anymore. The pandemic has blurred this boundary between work and life. This summer, when I worked at home, I found that to the extent I was able to get concentrated time, I spent it working. Before the pandemic, l'd been trying to catch up on the older writings of Michael Rutter, in which he defined concepts of resilience around exposure to adverse events. It's not always the easiest read, but his papers certainly offer lots to think about.

\section{S: What journals or magazines do you subscribe to?}

ME: I do not have favorite journals. I look for good papers, irrespective of journal. I'm very skeptical of the things that get published in high-impact journals. My experience is that it's not the quality of the work that determines whether and where it gets published, but a scientist's connections within the field and the ability to package the work.

\section{S: Are you active on social media?}

ME: Not very. I've never shied away from controversial topics, but I find the level of engagement 
on social media to be problematic. It only allows simplistic and superficial positions. I am on Twitter, and it's been fine, except that I don't contribute to debates because I find it difficult to narrow down my thoughts and pick a position without the space to justify it. I would also rather be selective in what I look at and read. On the other hand, I admire the power of social media and what it can do when used for positive purposes.

\section{S: What do you eat or drink while you're working?}

ME: My morning coffee, which is the ritual I mentioned. And then, in the afternoon, I try to remember to drink lots of sparkling water, but it doesn't always happen.

\section{S: Does your lab have any traditions?}

ME: My team has a spontaneous ability to self-organize and take initiative. We have something called 'cookie time,' a weekly drop-in virtual session where people just hang out and chat and eat a cookie. Over the summer, we had a few in-person picnics on Mount Royal, too.

\section{S: How many unread emails do you have in your inbox right now?}

ME: I am proudly an inbox zero person. I'm looking now, and I'm at 29. But that's because l've been in meetings all morning.

\section{S: What's your secret?}

ME: I think it was Geri Dawson who got me hooked on the inbox zero method - if it takes less than two minutes to reply, you do it. If it's something you have to think about, you schedule it and put it somewhere you can find it. I also feel good about deleting emails, in a way that I was not before.

\section{S: What is the most rewarding part of your job?}

ME: A lot of us go into science because we want to exert some impact on the world; we want to change the world. This is not something you can only dream about. It's a matter of learning to find and capture opportunities for that in your day-to-day work. This may sound idealistic, but it's actually a very strategic way to approach research - and it's led to tremendous success for me and my team.

Cite this article: https://doi.org/10.53053/QYFL6534 